\title{
Voltage regulation of an asynchronous wind turbine using STATCOM and a control strategy based on a combination of single input fuzzy logic regulator and sliding mode controllers
}

Mohammed Mokhtari', Smail Zouggar ${ }^{2}$, Nacer K. M'sirdi ${ }^{3}$, Mohamed Larbi Elhafyani ${ }^{4}$

${ }^{1,2,4}$ Laboratory of Electrical Engineering and Maintenance, School of Technology, University Mohammed $1^{\text {st }}$, Morocco

${ }^{3}$ Laboratory of Systems and Information Sciences of Aix Marseille University, France

\section{Article Info}

Article history:

Received Jan 17, 2019

Revised Jul 22, 2019

Accepted Aug 3, 2019

\section{Keywords:}

Asynchronous Wind Turbine Single Input Fuzzy Logic Regulator

Sliding Mode Controllers

STATCOM

Voltage Regulation

\begin{abstract}
In the literature, it is well known that reactive power management is the greatest challenge in wind turbine based on a three-phase self-excited induction generator. Any variation of wind speed or load causes a variation on the needed reactive power and thus a voltage fluctuation. Flexible AC transmission device such as STATCOM become then a necessity to prevent voltage instability and hence voltage collapse at the point of common coupling. This paper proposes so a new control strategy for voltage regulation of an asynchronous wind turbine based on a combination of a single input fuzzy logic regulator and a sliding mode controller. Compared to the classical control strategy with PI regulators, the performance of the proposed compensator has been significantly improved when it is controlled by the new approach and the system have shown more robustness and stability regarding external disturbances. The present document traits so the modelling of the power system, the simulation results and the controller's scheme and design.
\end{abstract}

This is an open access article under the $\underline{C C B Y-S A}$ license.

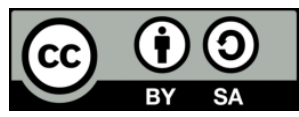

\section{Corresponding Author:}

Mohammed Mokhtari,

Laboratory of Electrical Engineering and Maintenance,

University Mohammed 1st,

BP 473 Al Quds University Complex, Oujda 60000, Morocco.

Email: mohammed.mokhtari@outlook.com

NOMENCLATURE

$\begin{array}{cl}\rho & \text { Air density. } \\ \mathrm{R} & \text { Blades length. } \\ \mathrm{V} & \text { Wind Speed. } \\ C_{p}(\lambda) & \text { Aerodynamic performance of the turbine. } \\ \Omega_{\text {turbine }} & \text { Turbine shaft speed. } \\ C_{g} & \text { Transmitted torque to the shaft of the IG } \\ C_{a e r} & \text { Aerodynamic torque. } \\ \mathrm{M} & \text { Multiplier ratio. } \\ \Omega_{m e c} & \text { Mechanical speed of the IG shaft } \\ \omega_{r} & \text { IG shaft angular velocity. }\end{array}$

$V_{\alpha s}, V_{\beta s}$

$i_{\alpha s}, i_{\beta s}$

$i_{\alpha r}, i_{\beta r}$

$i_{\alpha m}, i_{\beta m}$

$\varphi_{\alpha r}, \varphi_{\beta r}$

$\varphi_{\alpha s}, \varphi_{\beta s}$

$R_{r}, R_{s}$

$L_{m}$

$l_{s}, l_{r}$

$\omega_{s}$
Stator terminal voltages in $\alpha \beta$ reference.

Stator phase current in $\alpha \beta$ reference.

Rotor phase current in $\alpha \beta$ reference.

Magnetizing current in $\alpha \beta$ reference.

Rotor flux in $\alpha \beta$ reference.

Stator flux in $\alpha \beta$ reference.

Per phase rotor and stator resistances.

Magnetizing reactance.

Stator and rotor leakage reactances.

Synchronous angular velocity.

\section{INTRODUCTION}


Wind energy is abundant and endowed with inexhaustible potential. It is today one of the best sources of sustainable electricity supply for global development. Compared with other generators, SelfExcited Induction Generator (SEIG) applied in variable speed wind turbine system gives more advantages for an isolated micro-grid. Its robustness and low cost qualities makes it perfectly suited for use in some extreme wind and load conditions. However, the terminal voltage stability of the Induction Generator (IG) cannot be guaranteed with only a shunt connection to a fixed capacitor bank. Thus, several voltage regulation schemes have been proposed by researchers using mechanically switched capacitors, synchronous condensers and Flexible AC transmission (FACT) devices such as the Static Var Compensator (SVC) or more recently the Static Synchronous Compensator (STATCOM) $[1,2]$.

In Reference [3] thyristor-controlled static var compensator have been reported to provide the required reactive power for voltage support and transient stability improvement of an electrical network with wind generator. In Reference [4] the authors proposed a STATCOM with an energy storage system (STATCOM/ESS) to supply reactive power compensation, voltage regulation and transient stability enhancement, for wind turbines equipped with fixed-speed induction generators.

A comparison has been made in reference [5] between SVC and STATCOM showing that, for improving reactive power of a wind farm with cage induction generators, STATCOM is more useful than SVC. This is due to its higher control bandwidth and the additional capability of providing higher currents at low voltage levels.

In this work, the topology using STATCOM have been chosen. Several control approaches, from the classical to intelligent ones, have been used in the literature. Generally, there are two control objectives implemented in STATCOM. One of them uses the AC voltage regulation at PCC and the other is the DC voltage regulation across its capacitor. In the conventional scheme, linear control techniques based on a decoupled dq axis control approach with four Proportional Integral (PI) regulators cascaded were mainly used. In [6], the authors proposed to design the PI controllers with an anti-wind-up gain, while in [7] the authors have designed the linear PI controllers based on approximation around an operating point by the Taylor series. The problem of this methods is that the control design depends on the operating point. This is not well advised in the event of large disturbances. Furthermore, the chosen set of the PI gainsis held fixed during operation of STATCOM. Since wind speed and load changes with time those parameters cannot be suitable for all working conditions.

In addition, due to the non-linearity of the studied system, the inaccuracy of its parameters and measurement and the uncertainty introduced by the disturbances, this approach presents limitation when fast, robust and high precision responses are required in real-time implementation. Therefore, in [8] control strategies based on adaptive PI control, which can adapt the control gains have been proposed to track the variations. In [9] a fuzzy PI control method is proposed to tune PI controller gains. In [10] authors introduced a single neuron Neural Network as a self-tuning and robust PI controller. However, these controllers need mathematical models of the studied system and are therefore sensitive to parameter variation.

Moreover, in [11], [12] and [13], Linear Quadratic State Feedback Control is proposed. In [14], [15] and [16] a variable structure Fuzzy Logic control is used. In [17] and [18] a sliding mode control strategy is used. In [19] a Fuzzy sliding mode control is tested. In [20] the backstepping method is adopted and in [21] authors applied an $\mathrm{H} \infty$ controller to have better response in steady and transient states respectively. In most of the aforementioned works, researchers have tried to use a stable controllers but too complex in order to make it capable of reacting to various conditions in the best possible way.

Consequently, the main contribution of this paper can be summarized as the use and control of STATCOM for regulating the voltage output of an asynchronous wind turbine at variable wind speed and load conditions, using a relatively new adaptive method based on a combination of a Single Input Fuzzy Logic regulator and a Sliding Mode Controllers. The main features of this control approach is its insensitivity to the modeling errors and the system parameters variations. The proposed controller has a simple structure, needs a low computations time, has a good self-tuning ability and depends only on the error between the reference and the measured value to reduce voltage fluctuation at all possible conditions. Therefore, this control approach can be easily used in real time implementation.

The organization of this paper is as follows. It starts with the modelling of the studied asynchronous wind turbine and STATCOM, then focuses on the description of the proposed control approach and the design of the proper controllers, to finally discuss and analysis the simulated results.

\section{POWER SYSTEM MODELING}




\subsection{Asynchronous Wind Turbine Model}

Multiple versions of wind turbine model have recently been designed and can be obtained throughout the literary works $[2,18,22,23]$. Due to the fact that the electric response of the system is our bottom line, the observed model in Figure 1 is therfore presumed:

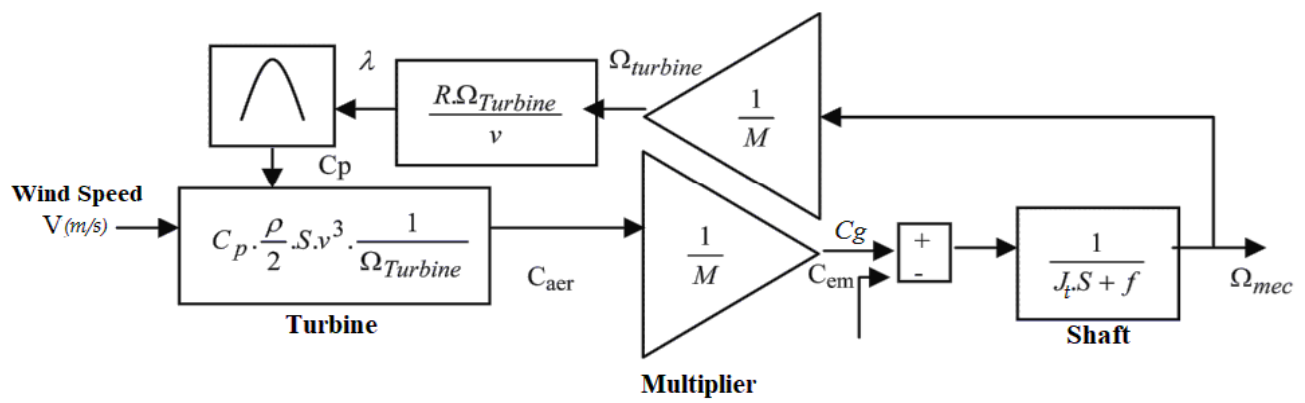

Figure 1. Schematic diagram of the wind turbine model.

The self-excited induction generator design established in this paper is expressed in $\alpha \beta$ reference frame as preseented in Figure 2. It needs to be mentioned that $L_{m}$ depends on the magnetizing current $i_{m}$ [24]. This dependency has actually been experimentally identified in former work as referred in [2] and integrated in Matlab/Simulink model settings.

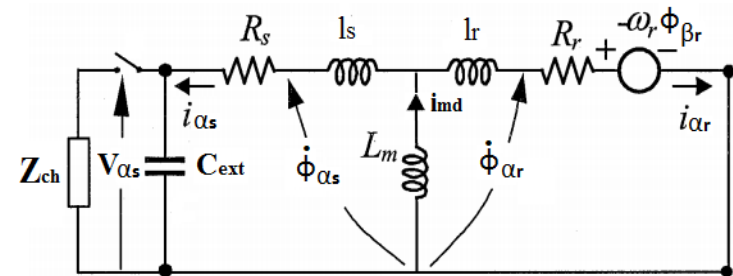

(a)

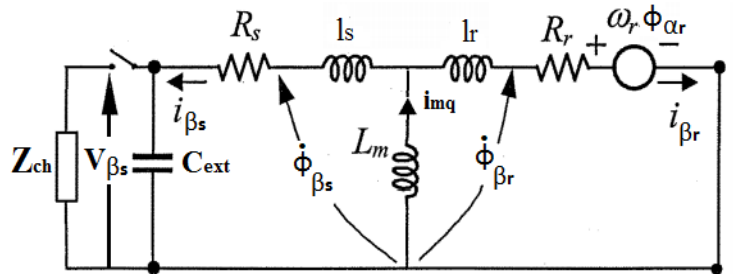

(b)

Figure 2. Equivalent circuit of the SEIG in $\alpha \beta$ reference frame.

The electro-magnetic torque generated by the induction machine is described by:

$$
C_{e m}=p \cdot \frac{L_{m}}{L_{r}}\left(\varphi_{\alpha r} \cdot i_{\beta s}-\varphi_{\beta r} i_{\alpha s}\right)
$$

\subsection{Static Synchronous Compensator Model}

The basic concept of STATCOM is the creation of an adjustable voltage source using a Voltage Source Inverter (VSI) and 3 Phase SPWM power converter technology which include IGBTs. The AC side of the VSI is coupled to the asynchronous wind generator via a reactance and its DC side is connected to a capacitor. The active as well as reactive power transfer between both systems results from the voltage difference across the reactance and may be managed by the Modulation Index MI and the relative phase angle $\alpha[17]$.

The modelling of STATCOM, Figure 3, is examined in the lines listed below and also defined in Park reference frame [25]. We designate the reference frame coordinate such as the d-axis is constantly coincident with the instantaneous system voltage vector and the q-axis remains in quadrature with it [26]. The formulas defining the AC side of STATCOM in the dq reference frame are provided by:

$$
\frac{d}{d t}\left[\begin{array}{l}
i_{\text {otd }} \\
i_{\text {otq }}
\end{array}\right]=\left[\begin{array}{cc}
-\frac{R_{c}}{L_{c}} & \omega_{s} \\
-\omega_{s} & -\frac{R_{c}}{L_{c}}
\end{array}\right] \cdot\left[\begin{array}{l}
i_{\text {otd }} \\
i_{\text {otq }}
\end{array}\right]+\frac{1}{L_{c}}\left[\begin{array}{l}
V_{\text {sd }}-V_{\text {otd }} \\
V_{\text {sq }}-V_{\text {otq }}
\end{array}\right]
$$

The DC voltage and current of STATCOM are interconnected by: 


$$
\frac{d V_{d c}}{d t}=\frac{i_{d c}}{C_{d c}}
$$

Given that SPWM method is applied to STATCOM, and all the voltage harmonics generated by the VSI are ignored, the formulas associating the DC side and AC side of STATCOM can be described as:

$$
\begin{aligned}
& {\left[\begin{array}{l}
V_{\text {otd }} \\
V_{\text {otq }}
\end{array}\right]=\text { MI. } V_{\text {dc }} \cdot\left[\begin{array}{l}
\cos (\alpha) \\
\sin (\alpha)
\end{array}\right]} \\
& i_{\text {dc }}=\text { MI. }\left[\begin{array}{ll}
i_{\text {otd }} & i_{\text {otq }}
\end{array}\right] \cdot\left[\begin{array}{l}
\cos (\alpha) \\
\sin (\alpha)
\end{array}\right]
\end{aligned}
$$

Where $M I$ and $\alpha$ are the control parameters of STATCOM calculated from the voltage references using the following equations:

$$
\begin{aligned}
& M I=\frac{\sqrt{V_{\text {otd_ref }}^{2}+V_{\text {otq_ref }}^{2}}}{\alpha=\tan ^{-1}\left(\frac{V_{\text {otc_ref }}}{V_{\text {otd_ref }}}\right)}
\end{aligned}
$$

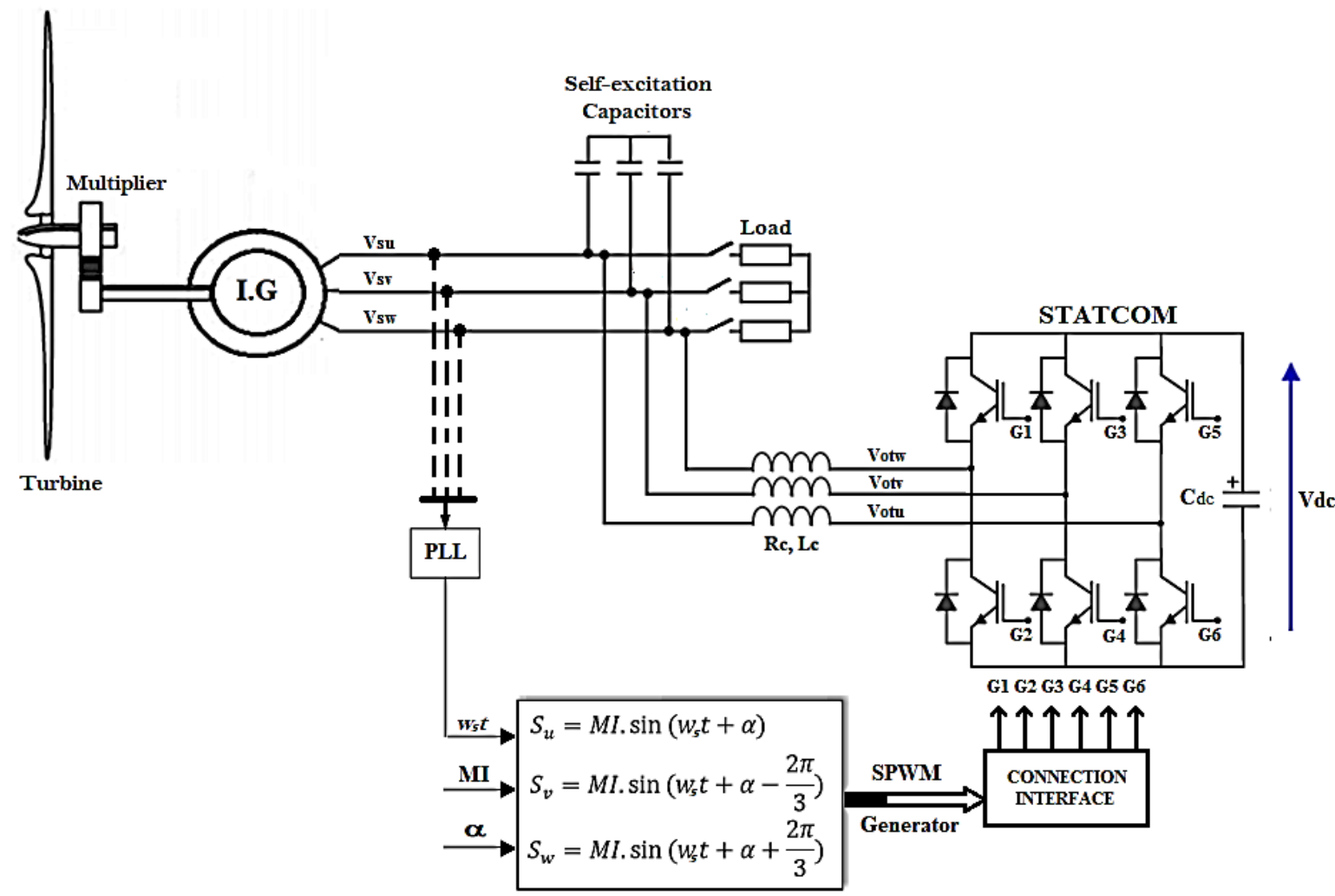

Figure 3. Schematic diagram of the asynchronous wind turbine with STATCOM

\section{CONTROL STRATEGY ANALYSIS}

To enhance voltage stability of the wind turbine regardless of wind speed or load variation, STATCOM need to transfer reactive power $Q(t)$ to the SEIG to minimize the AC voltage perturbation and should consume active power $P(t)$ to maintain the DC voltage at its referenced value.

Yet, equation (6) reveals that the control of the active power $P(t)$ may be done using the d-axis current $i_{\text {otd }}$ while the q-axis current $i_{\text {otq }}$ can help in the control of the reactive power $Q(t)$ : 


$$
\begin{aligned}
& P(t)=\frac{3}{2} v_{s d} i_{o t d} \\
& Q(t)=-\frac{3}{2} v_{s d} i_{o t q}
\end{aligned}
$$

Therefore, to accomplish the intended power control results, a feedback current controllers need to be adopted along with the voltage control loops to remove the steady state error entirely and assist the injected currents $i_{\text {otd }}$ and $i_{\text {otq }}$ to match their references.

Meanwhile, It may be observed from equation (2) that both elements of the injected current $i_{\text {otd }}$ as well as $i_{\text {otq }}$ are cross-coupled via the term $\omega_{s} L_{c}$. Any kind of adjustment in the direction of one axis induces a modification in the current in the other direction. Therefore, it's required to remove the interaction between the currents. In this paper, the classical decoupled Watt-Var approach is applied [3]. The two new variables presented in equation (7) are the output from the suggested control strategy.

$$
\begin{aligned}
& \mathrm{V}_{\text {otd }}{ }^{*}=\mathrm{i}_{\text {otq }} \omega_{\mathrm{s}} \mathrm{L}_{\mathrm{c}}+\mathrm{V}_{\text {sd }}-\mathrm{V}_{\text {otd_ref }} \\
& \mathrm{V}_{\text {otq }}{ }^{*}=\mathrm{i}_{\text {otd }} \omega_{\mathrm{s}} \mathrm{L}_{\mathrm{c}}+\mathrm{V}_{\text {sq }}-\mathrm{V}_{\text {otq_ref }}
\end{aligned}
$$

The control technique in Figure 4 operates so with two control loops to compute $V_{\text {otd }}{ }^{*}$ and $V_{\text {otq }}{ }^{*}$ that guarantee reference tracking of $V_{s}$ as well as $V_{d c}$.

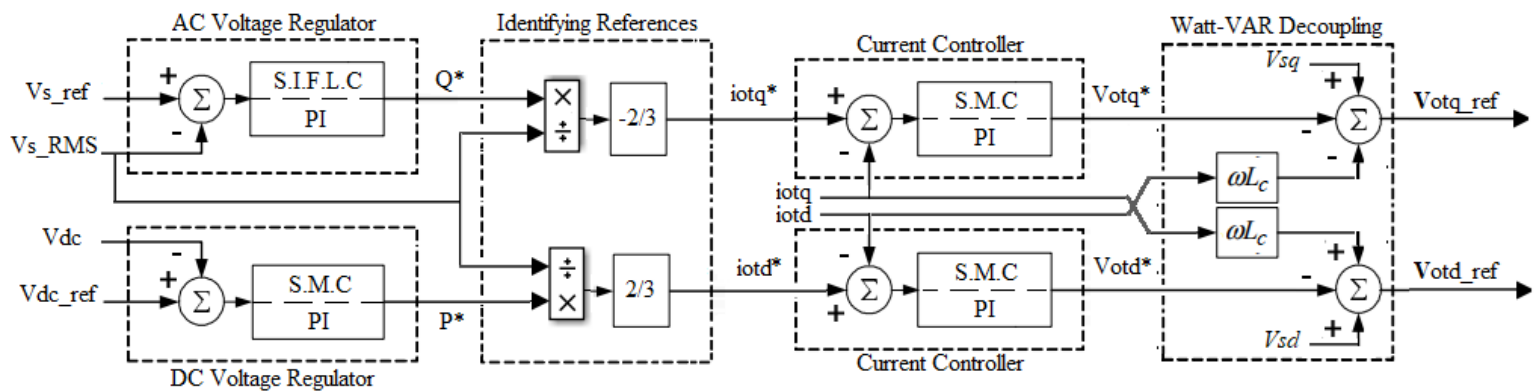

Figure 4. Voltage and current loops of the proposed control strategy

To identify the appropriate parameters of the PI controllers in Figure 4, Bode plot and the Tuning tool in Matlab/Simulink software have been employed as explained in reference [27]. The selected values are outlined in Table 1:

Table 1. PI parameters

\begin{tabular}{cccc}
\hline & Transfert Function & $K_{p}$ & $K_{i}$ \\
\hline Current Controllers & \multirow{2}{*}{$K_{i}$} & 5.393 & 1726.072 \\
DC Voltage Regulator & \multirow{2}{*}{$K_{p}+\frac{1.199}{s}$} & -11 & 2.029 \\
AC Voltage Regulator & & -0.05 \\
\hline
\end{tabular}

\subsection{Proposed sliding mode current controllers}

The purpose of this section is to investigate the suggested sliding mode current controllers that will likely replace the standard PI controllers. This procedure basically involves two phases: the selection of the sliding mode surface area and its stability evaluation.

Since sliding mode control is known for its fast global convergence, simplicity of implementation as well as its high robustness to external perturbation. The current component $i_{\text {otd }}$ and $i_{\text {otq }}$ of the inner loops will better track their references values $[14,17]$.

\subsubsection{Sliding Surface design}

The control goals are to track or slide along the predefined current references $i_{\text {otdq }}^{*}$. For this objective, the sliding surfaces are established as: 
$S_{d}=i_{o t d}-i_{o t d}^{*}$

$S_{q}=i_{o t q}-i_{o t q}^{*}$

The sliding surfaces derivatives are provided by:

$$
\begin{gathered}
\frac{d S_{d}}{d t}=-k_{d} \operatorname{sign}\left(S_{d}\right) \\
\frac{d S_{q}}{d t}=-k_{q} \operatorname{sign}\left(S_{q}\right)
\end{gathered}
$$

With $k_{d}$ and $k_{q}$ two positive constants.

However, from (8) we have:

$$
\begin{aligned}
& \frac{d S_{d}}{d t}=\frac{d i_{o t d}}{d t}-\frac{d i_{o t d}^{*}}{d t} \\
& \frac{d S_{q}}{d t}=\frac{d i_{o t q}}{d t}-\frac{d i_{o t q}^{*}}{d t}
\end{aligned}
$$

From (2) and (7), we can write:

$$
\begin{aligned}
& \frac{d i_{o t d}}{d t}=-\frac{R_{c}}{L_{c}} i_{o t d}+\frac{V_{o t d}{ }^{*}}{L_{c}} \\
& \frac{d i_{o t q}}{d t}=-\frac{R_{c}}{L_{c}} i_{o t q}+\frac{V_{o t q}{ }^{*}}{L_{c}}
\end{aligned}
$$

Consequently, STATCOM voltage references are deduced from:

$$
\begin{aligned}
& V_{\text {otd_n }}{ }^{*}=-L_{c} k_{d} \operatorname{sign}\left(S_{d}\right)+R_{c} i_{\text {otd }} \\
& V_{\text {otq_n }}{ }^{*}=-L_{c} k_{q} \operatorname{sign}\left(S_{q}\right)+R_{c} i_{\text {otq }}
\end{aligned}
$$

When the sliding mode occurs on the sliding surface, we will have $S_{d q}=\dot{S}_{d q}=0$, and thus the dynamic behaviour of the tracking problem in equation (10) is equivalently controlled by:

$$
\begin{aligned}
& \frac{d s_{d}}{d t}=\frac{d i_{\text {otd }}}{d t}-\frac{d i_{\text {otd }}^{*}}{d t}=-\frac{R_{c}}{L_{c}} i_{o t d}+\frac{V_{\text {otd_eq }}}{L_{c}}=0 \\
& \frac{d S_{q}}{d t}=\frac{d i_{\text {otq }}}{d t}-\frac{d i_{\text {otq }}^{*}}{d t}=-\frac{R_{c}}{L_{c}} i_{\text {otq }}+\frac{V_{\text {otq_eq }}}{L_{c}}=0
\end{aligned}
$$

From (13), we can deduce that:

$$
\begin{aligned}
& V_{\text {otd_eq }}{ }^{*}=R_{c} i_{\text {otd }} \\
& V_{\text {otq_eq }}{ }^{*}=R_{c} i_{\text {otq }}
\end{aligned}
$$

Finally, the sliding mode current controllers are designed as:

$$
\begin{aligned}
& V_{o t d}{ }^{*}=V_{\text {otd_n }}{ }^{*}+V_{\text {otd_eq }}{ }^{*}=-L_{c} k_{d} \operatorname{sign}\left(S_{d}\right)+R_{c} i_{\text {otd }}+R_{c} i_{\text {otd }} \\
& V_{\text {otq }}{ }^{*}=V_{\text {otq_n }}{ }^{*}+V_{\text {otq_eq }}{ }^{*}=-L_{c} k_{q} \operatorname{sign}\left(S_{q}\right)+R_{c} i_{\text {otq }}+R_{c} i_{\text {otq }}
\end{aligned}
$$

\subsubsection{Stability analysis:}

The Lyapunov function defined in equation (16) is required to ensure the convergence of the proposed controllers.

$$
V=\frac{1}{2} S_{d}^{2}+\frac{1}{2} S_{q}^{2}
$$

To confirm the stability of the system all over the sliding surfaces, the condition in (17) need to be respected.

$$
\dot{V}<0
$$


By differentiating equation (16), we obtain:

$$
\dot{V}=S_{d} \dot{S_{d}}+S_{q} \dot{S_{q}}
$$

And by replacing (9) into (18), we have:

$$
\dot{V}=-S_{d} k_{d} \operatorname{sign}\left(S_{d}\right)-S_{q} k_{q} \operatorname{sign}\left(S_{q}\right)
$$

It results:

$$
\dot{V}=-k_{d}\left|S_{d}\right|-k_{q}\left|S_{q}\right|<0
$$

Hence, we have verified that the global asymptotical stability is guaranteed.

\subsection{Proposed AC voltage regulator}

The single input fuzzy logic controller developed in this work replaces the conventional AC voltage PI regulator in Figure 4. The selection of this form of control is mainly due to its capacity to manage tolerance as well as uncertainty in the decision-making procedure without the requirement of a comprehensive mathematical model of the system.

The suggested controller is so built as shown in Figure 5. The error between the referenced and the measured RMS value of the generated voltage $V_{S}$ is selected as an input signal while $d Q^{*}$ as an output signal.

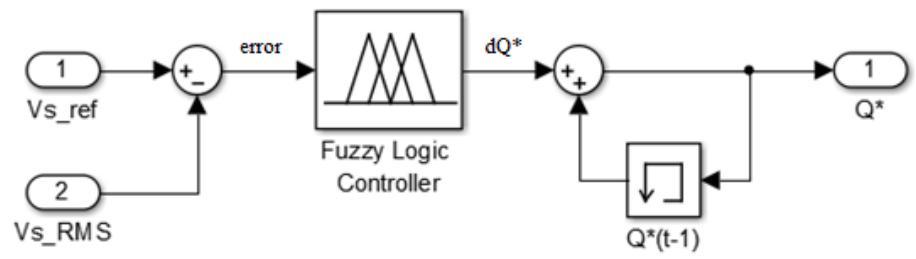

Figure 5. Single input fuzzy logic regulator

The reference reactive power to be exchanged with the induction generator to keep the AC voltage stable is computed with the following formula:

$Q^{*}=\sum d Q^{*}(t)$

- When $V s \_R M S$ is equal to $V s \_r e f$ value, error is equal to zero and $d Q^{*}$ must be equal to zero to keep $Q^{*}$ at its previous value to avoid injection or absorption of any reactive power.

- When $V s_{-} R M S$ is greater than Vs_ref value (inductive mode), error is negative so $d Q^{*}$ must be positive as well as $Q^{*}$ and its value should increase to absorb the excess of reactive power forcing the generated voltage to drop to the rated value.

- When $V s \_R M S$ is less than Vs_ref value (capacitive mode), error is negative so $d Q^{*}$ must be negative as well as $Q^{*}$ and its value should decrease to inject the needed reactive power forcing the generated voltage to rise up to the rated value.

In this paper, the single input fuzzy logic controller is a Mamdani-type defined by seven triangular rule-based-membership functions as shown in Figure 6. 

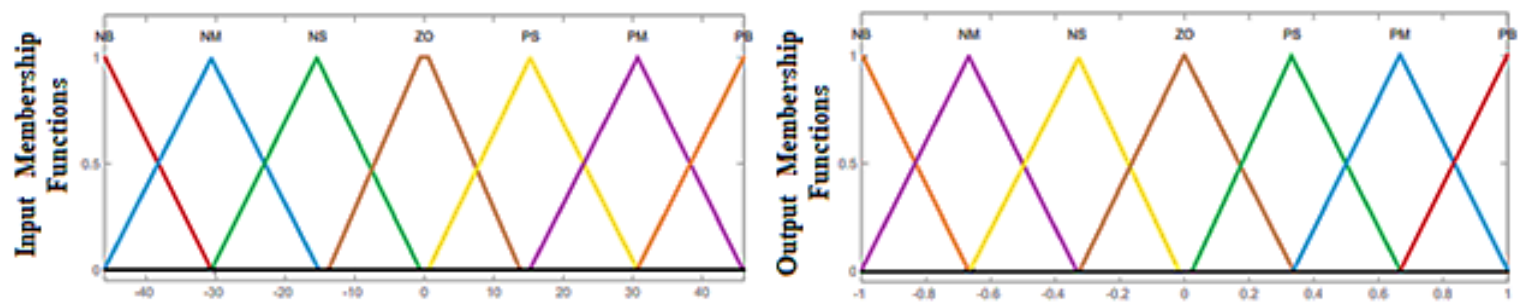

Figure 6. Input and output membership functions of the SIFLC

The seven linguistic variables used are Negative Big (NB), Negative Medium (NM), Negative Small (NS), Zero (ZO), Positive Small (PS), Positive Medium (PM) and Positive Big (PB). The 7 rules have been built as represented in Figure 7.
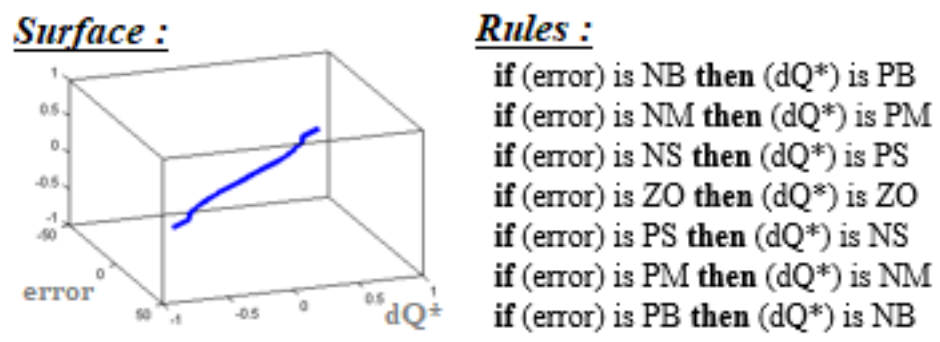

Figure 7. The chosen rules of the SIFLC

\subsection{Proposed sliding mode $\mathrm{DC}$ voltage regulator}

To compensate losses in the DC circuit, STATCOM needs to absorb from the wind generator the active power deduced from the following sliding surface:

$$
S_{p}=V_{d c}-V_{d c_{-} r e f}
$$

The sliding surface derivative can be obtained by:

$$
\frac{d s_{p}}{d t}=-k_{p} \operatorname{sign}\left(S_{p}\right)
$$

With $k_{p}$ a positive constant. From (22) we have:

$$
\frac{d s_{p}}{d t}=\frac{d V_{d c}}{d t}-\frac{d V_{d c_{-} r e f}}{d t}
$$

Yet, we know that:

$$
\frac{d V_{d c}}{d t}=\frac{i_{d c}}{C_{d c}}=\frac{P_{d c \_n}}{C_{d c} \cdot V_{d c}}
$$

From (23), (24) and (25) we can deduce:

$$
P_{d c_{-} n}=-k_{p} \cdot C_{d c} \cdot V_{d c} \cdot \operatorname{sign}\left(S_{p}\right)
$$

In this case, the expression of the equivalent control laws is null and can be deduced from (25) by assuming that $\dot{S}_{p}=0$ :

$$
\frac{d S_{p}}{d t}=\frac{d V_{d c}}{d t}-\frac{d V_{d c \_r e f}}{d t}=\frac{i_{d c}}{C_{d c}}=\frac{P_{d c \_e q}}{C_{d c} \cdot V_{d c}}=0
$$


Finally, we can write:

$$
P_{d c}^{*}=P_{d c_{-} n}{ }^{*}=-k_{p} \cdot C_{d c} \cdot V_{d c} \cdot \operatorname{sign}\left(S_{p}\right)
$$

By adopting the exact same approach applied in sliding surface current controllers, the stability of the selected surface for DC voltage controller can be confirmed.

The sign function, as well as equation (23) are the standard SMC. To decrease the chattering phenomenon, the sign function is replaced by the continuous function sigmoid described by:

$$
\operatorname{sigmoid}\left(S_{p}\right)=\left[\frac{2}{\left(1+e^{-\lambda . S_{p}}\right)}\right]-1
$$

With $\lambda$ a constant parameter.

\section{SIMULATION RESULTS \& DISCUSSION}

In this section the profile of the produced RMS voltage when the asynchronous wind turbine is under varying wind speed and load conditions will be analyzed and synthesized for both no compensation mode and compensation mode. Figure 8 reveals the simulation results using the control approach based on PI controllers as well as the one employing single input fuzzy logic and sliding mode controllers.During the starting phase from the instant 0 s to $2 \mathrm{~s}$, STATCOM is not yet connected since the produced voltage has not reached the regulation zone set to $+/-20 \%$ of $V_{s}$ ref. After the second two, if the PI controllers are used, the output voltage grows exponentially to $230 \mathrm{~V}$ with a good settling time and without any overshoot because PI parameters have been designed under no load and $10.5 \mathrm{~m} / \mathrm{s}$ wind speed conditions. But if the SIFLC is used along with the sliding mode controllers the $V_{S_{-} R M S}$ will reach $254.4 \mathrm{~V}$ then drops in $0.5 \mathrm{~s}$ to $230 \mathrm{~V}$ which still considered as a good transient response. At the 4 th second and 6th second we observe that $V_{S_{-} R M S}$ varies at no compensation mode when wind speed drops at no load from $10.5 \mathrm{~m} / \mathrm{s}$ to $8 \mathrm{~m} / \mathrm{s}$ then rises again to $9 \mathrm{~m} / \mathrm{s}$. However, using the new approach STATCOM was able to regulate the generated voltage in $0.4 \mathrm{~s}$ and $0.46 \mathrm{~s}$ respectively, unlike the PI controllers which have made the system unstable with an oscillatory response. Finally, when the system become at full load at the 8th second the proposed strategy have once more proved its efficiency since $V_{S_{-} R M S}$ drops to $183 \mathrm{~V}$ then stabilizes at the rated value in less than $0.03 \mathrm{~s}$. PI controllers in the other hand have failed to rise the produced voltage to $230 \mathrm{~V}$. We can conclude so that using the suggested structure of control, the single input fuzzy logic controller combined with the sliding mode controllers has successfully regulated the SEIG voltage terminals at its referenced value with excellent dynamic and static responses.
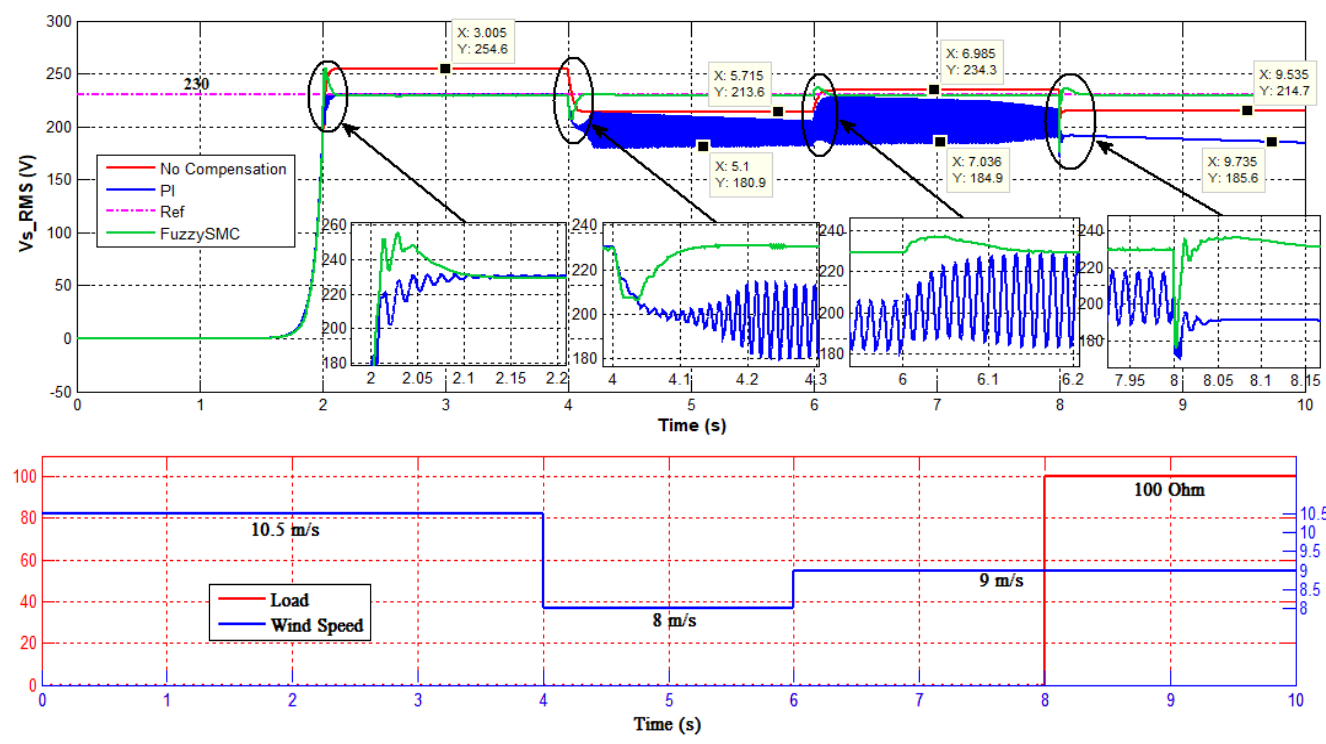

Figure 8. Asynchronous wind turbine voltage with and without compensation at different wind speed and load state 
To be able to minimize AC voltage variation, the SIFLC needs to react to wind speed and load changes with a good dynamic forcing so STATCOM to operate in both capacitive and inductive mode. Figure 9 reveals the exchanged reactive power between the SEIG and STATCOM when PI controllers or fuzzy sliding mode controllers are used.

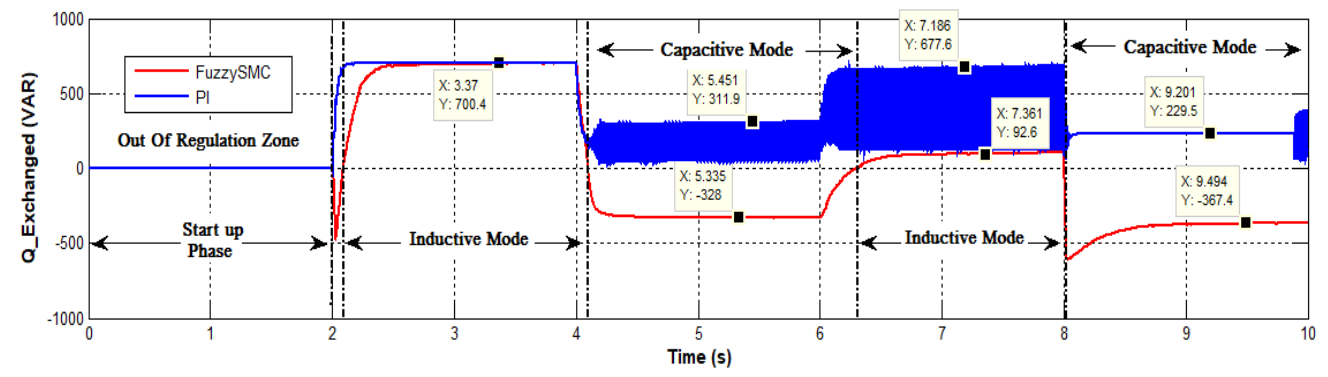

Figure 9. The exchanged reactive power between STATCOM and the asynchronous wind turbine

Furthermore, compared to PI controllers results in Figure 11, the injected current $i_{\text {otq }}$ that contribute to the control of the reactive power provides in Figure 10 a good tracking responses and robust characteristics when the proposed controllers are applied. The observed chattering in the steady-state is acceptable due to its small variation and can be minimized in practice by choosing an optimal value of $k_{q}$.

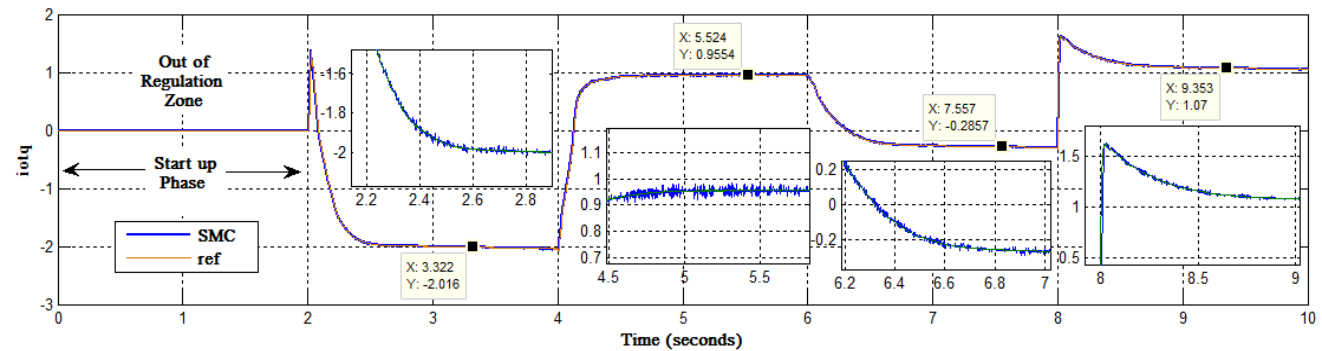

Figure 10. STATCOM q_axes current variation as function of PCC voltage using SMC

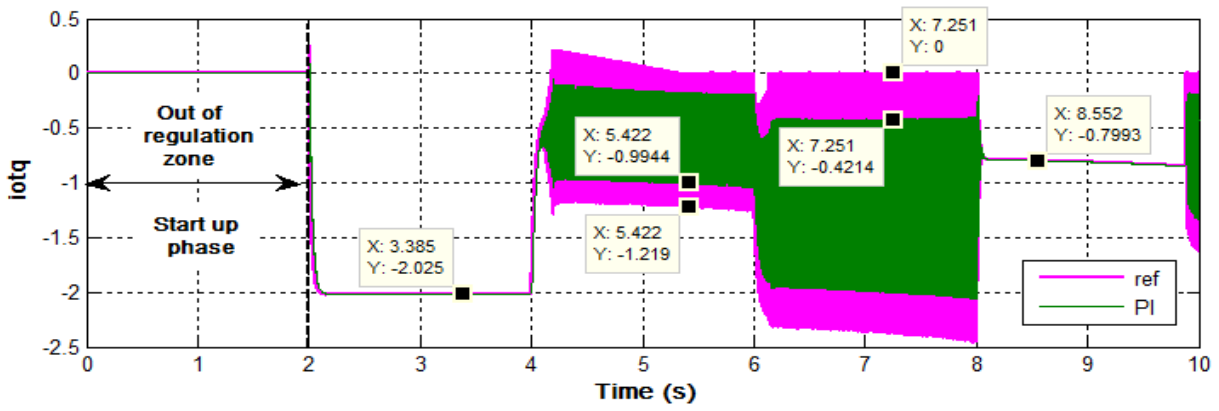

Figure 11. STATCOM q_axes current variation as function of PCC voltage using PI controllers

Also, in Figure 13 the simulation results show that sliding mode DC voltage controller was able, at $\mathrm{t}=2 \mathrm{~s}$, to rise $V_{d c}$ up to the referenced value just after the excitation of the SEIG. We can also notice that the settling time of $V_{d c}$ using sliding mode controller is better than PI controller which prove again the efficiency of proposed approach. Figure 12 is introduced to show that the chattering phenomenon produced using the sign function can be significantly reduced by the sigmoid function. 
The active power supplied by the aerogenerator to STATCOM in order to regulated $V_{d c}$ relies on the controllers used for simulation. When PI controller is applied, the active power reaches $27.55 \mathrm{~W}$ then falls to zero after 0.7 seconds since all losses are neglected, while it goes up till $42 \mathrm{~W}$ for $0.4 \mathrm{~s}$ when sliding mode controller is explored. This difference shown in Figure 14 allows SMC to have faster dynamic response.

Figure 15 shows that the injected current iotd reach a peak of 0.59 when PI controller is used while its value don't cross 0.11 and lasts longer when we switch to sliding mode controller. Both controllers presents good convergence characteristics which contribute to a good control performance of the active power exchanged between SEIG and STATCOM.

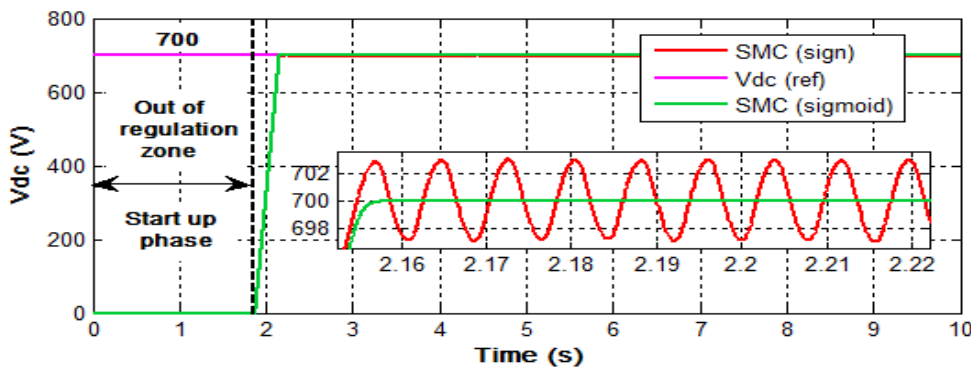

Figure 12. Vdc response using SMC with sign and sigmoid function

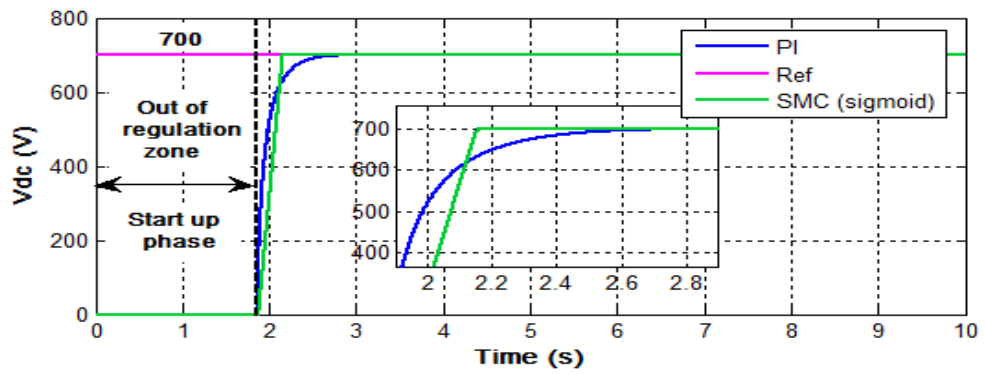

Figure 13. PI vs SMC DC voltage response

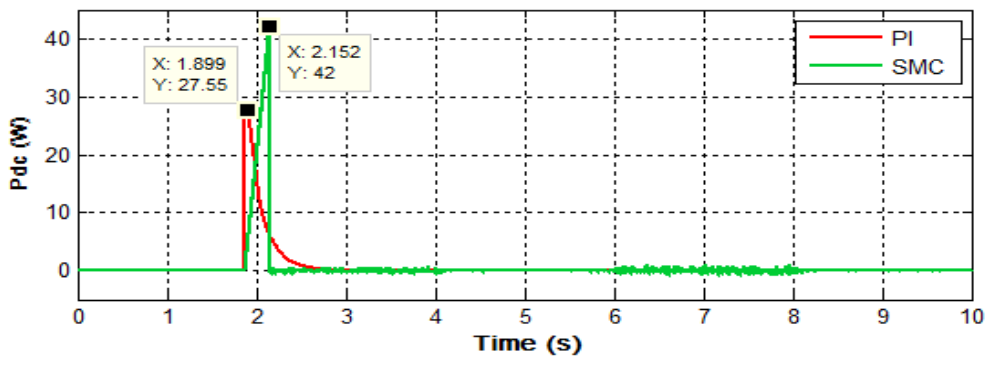

Figure 14. STATCOM active power

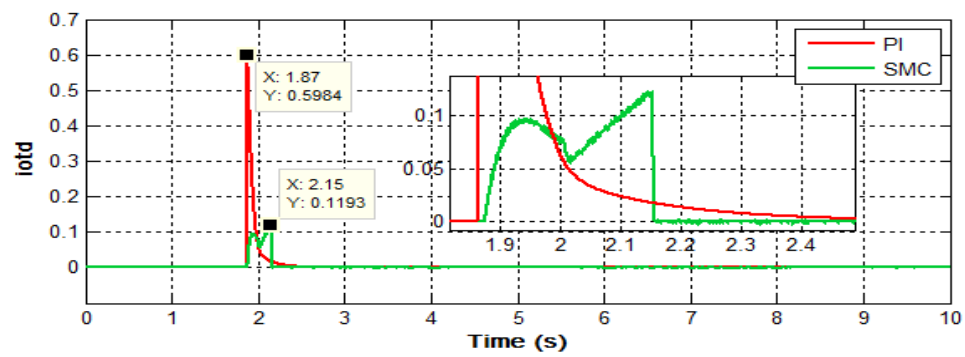

Figure 15. STATCOM d_axes current variation 


\section{CONCLUSION}

This paper has proposed a novel voltage control approach for asynchronous wind turbine based on

STATCOM. The new configuration uses a combination of single input fuzzy logic and sliding mode controllers in order to compute the required converter's control references that ensure stability of both AC and DC voltages. The performance efficiency of the current control loops has been first verified by the theoretical investigation that confirmed its convergence. Then the validity of the suggested voltage control scheme has been established through simulation results analysis which revealed excellent characteristics of voltage profile regarding references tracking, response time, robustness and disturbance rejection. Moreover, a comparison have been made with the conventional PI controllers to prove the superior performance of the proposed approach. The future challenge will be then to develop a laboratory wind turbine emulator test bench allowing experimental validation of the proposed control strategy using real-time control board dspace 1104.

\section{REFERENCES}

[1] Alhalim, S. S. A., \& Alnabi, L. A., "Enhancement transient stability of wind power system of doubly-fed induction generator using STATCOM and PI controller", International Journal of Power Electronics and Drive Systems (IJPEDS), Vol. 10, No. 4, pp. 1977-1985, 2019.

[2] Mokhtari, M., Zouggar, S., Elhafyani, M. L., Ouchbel, T., Benzaouia, S., \& Fannakh, M., "Design, Simulation and Performance Analysis of Voltage Regulator Based on STATCOM for Asynchronous Wind Turbine", International Conference on Electronic Engineering and Renewable Energy. Springer, Singapore, pp. 498-509, 2018.

[3] Lahaçani, N. A., Aouzellag, D., \& Mendil, B., "Contribution to the improvement of voltage profile in electrical network with wind generator using SVC device", Renewable Energy, Vol. 35, No. 1, pp. 243-248, 2010.

[4] Hossain, M. J., Pota, H. R., \& Ramos, R. A., "Improved low-voltage-ride-through capability of fixed-speed wind turbines using decentralised control of STATCOM with energy storage system", IET generation, transmission \& distribution, Vol. 6, No. 8, pp. 719-730, 2012.

[5] Molinas, M., Suul, J. A., \& Undeland, T., "Low voltage ride through of wind farms with cage generators: STATCOM versus SVC”, IEEE Transactions on power electronics, Vol. 23, No. 3, pp. 1104-1117, 2008.

[6] Tripathi, S. M., \& Barnawal, P. J., "Design and Control of a STATCOM for Non-Linear Load Compensation: A Simple Approach", Electrical, Control and Communication Engineering, Vol. 14, No. 2, pp. 172-184, 2018.

[7] Hossain, M. J., Pota, H. R., \& Ramos, R. A., "Robust STATCOM control for the stabilisation of fixed-speed wind turbines during low voltages", Renewable Energy, Vol. 36, No. 11, pp. 2897-2905, 2011.

[8] Xu, Y., \& Li, F., “Adaptive PI control of STATCOM for voltage regulation”, IEEE transactions on power delivery, Vol. 29, No. 3, pp. 1002-1011, 2014

[9] Luo, A., Tang, C., Shuai, Z., Tang, J., Xu, X. Y., \& Chen, D. "Fuzzy-PI-based direct-output-voltage control strategy for the STATCOM used in utility distribution systems". IEEE Transactions on Industrial Electronics, Vol 56, No. 7, pp. 2401-2411, 2009.

[10] Khalghani, M. R., Shamsi-Nejad, M. A., Farshad, M., \& Khooban, M. H., "Modifying power quality's indices of load by presenting an adaptive method based on Hebb learning algorithm for controlling DVR", Automatika, Vol. 55, No. 2, pp. 153-161, 2014.

[11] Rao, P., Crow, M. L., \& Yang, Z., "STATCOM control for power system voltage control applications", IEEE Transactions on power delivery, Vol. 15, No. 4, pp. 1311-1317, 2000.

[12] Chen, W. L., \& Hsu, Y. Y., "Controller design for an induction generator driven by a variable-speed wind turbine", IEEE Transactions on Energy Conversion, Vol. 21, No. 3, pp. 625-635, 2006.

[13] Wang, K., \& Crow, M. L., "Power system voltage regulation via STATCOM internal nonlinear control", IEEE transactions on Power systems, Vol. 26, No. 3, pp. 1252-1262, 2010.

[14] Morris, S., Dash, P. K., \& Basu, K. P., “A fuzzy variable structure controller for STATCOM”, Electric Power Systems Research, Vol. 65, no. 1, pp. 23-34, 2003.

[15] Mohagheghi, S., Venayagamoorthy, G. K., Rajagopalan, S., \& Harley, R. G., "Hardware implementation of a mamdani fuzzy logic controller for a static compensator in a multimachine power system", IEEE Transactions on Industry Applications, Vol. 45, no. 4, pp. 1535-1544, 2009.

[16] Mak, L. O., Ni, Y. X., \& Shen, C. M., "STATCOM with fuzzy controllers for interconnected power systems", Electric Power Systems Research, Vol. 55, No. 2, pp. 87-95, 2000

[17] Hu, J., Shang, L., He, Y., \& Zhu, Z. Q., "Direct active and reactive power regulation of grid-connected DC/AC converters using sliding mode control approach". IEEE transactions on power electronics, Vol. 26, No. 1, pp. 210222, 2011.

[18] Belgacem, K., Mezouar, A., \& Essounbouli, N., "Design and Analysis of Adaptive Sliding Mode with Exponential Reaching Law Control for Double-Fed Induction Generator Based Wind Turbine", International Journal of Power Electronics and Drive Systems (IJPEDS), Vol. 9, No. 4, pp. 1534-1544, 2018.

[19] Benmeziane, M., Zebirate, S., Chaker, A., \& Boudjema, Z. "Fuzzy sliding mode control of doubly-fed induction generator driven by wind turbine", International Journal of Power Electronics and Drive Systems (IJPEDS), Vol. 10, No. 3, pp. 1592-1602, 2019.

[20] Rajendran, S., \& Debashisha, J. E. N. A., "Backstepping sliding mode control of a variable speed wind turbine for power optimization", Journal of Modern Power Systems and Clean Energy,Vol. 3, No. 3, pp. 402-410, 2015. 
[21] Li, Y. W., Blaabjerg, F., Vilathgamuwa, D. M., \& Loh, P. C., "Design and comparison of high performance stationary-frame controllers for DVR implementation", IEEE Transactions on Power Electronics, Vol 22, No. 2, 602-612, 2007.

[22] Zouggar, S., Zidani, Y., ELhafyani, M. L., Ouchbel, T., Seddik, M., \& Oukili, M., "Neural control of the selfexcited induction generator for variable-speed wind turbine generation", Sustainability in Energy and Buildings. Springer, Berlin, Heidelberg, pp. 213-223, 2012.

[23] Yin, X., Jiang, Z., \& Pan, L., "Recurrent neural network based adaptive integral sliding mode power maximization control for wind power systems", Renewable Energy, Vol. 145, pp. 1149-1157, 2020.

[24] M.L.Elhafyani, S.Zouggar, Y.Zidani, M. Benkaddour, "Permanent and Dynamic Behaviours of Self-excited Induction Generator In balanced", M. J. CONDENSED MATER Volume7, number 1, pp. 49-53, 2006.

[25] Singh, B., Murthy, S. S., \& Chilipi, R. S. R., "STATCOM-based controller for a three-phase SEIG feeding singlephase loads". IEEE transactions on energy conversion, Vol. 29, No. 2, 320-331, 2014.

[26] Jain, A., Joshi, K., Behal, A., \& Mohan, N., Voltage regulation with STATCOMs: Modeling, control and results. IEEE Transactions on Power delivery, Vol. 21, No. 2, pp. 726-735, 2006.

[27] Mokhtari, M., Zouggar, S., M'Sirdi, N. K., \& Elhafyani, M., "Behavior Analysis Of Asynchronous Wind Turbine In Presence Of Static Synchronous Compensator Operating With Fuzzy Logic Voltage Controller”, ECRES 2018, 6th Eur. Conf. Ren. Energy Sys. 25-27 June 2018.

\section{BIOGRAPHIES OF AUTHORS}

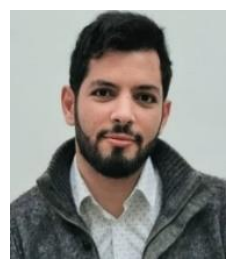

In 2012, as a student of an exchange program, Mohammed Mokhtari received a Master's degree in Automatics from University of Bordeaux, France and an Electrical Engineering degree from ENSEM of Hassan 2 University, Casablanca, Morocco. He is currently a PhD student at Higher Institute of Technology of Mohamed I University, Oujda, Morocco. His main research interest includes renewable energy and sustainable development as well as mechatronic system modelling and control.

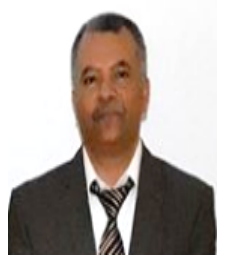

Zouggar Smail is currently full Professor at Higher Institute of Technology, Mohamed I University, Oujda, Morocco where he was until 2019 head of the Electrical Engineering and Maintenance Laboratory (LGEM). He received Master's degree in Electrical Engineering from Hassania School of Public Works (EHTP), Casablanca, Morocco in 1989. In 2001 he received $\mathrm{PhD}$ degree in Power Electronics, from Faculty of Science, Mohamed I University. His current research topics includes theory, design, modelling and characterization of hybrid system combining wind and photovoltaic system.

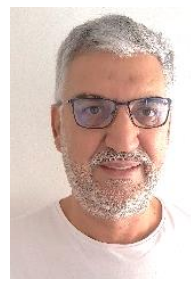

Nacer K M'Sirdi is professor at Polytech Marseille and Aix Marseille University (AMU). He got the Phd in Electronics at ENSERG shool of INPG Grenoble (1983) and the Doctorat d'Etat in adaptive signal processing for non-stationary signals at the ENSIEG of INPG, Grenoble, in 1988 (Laboratory of Automatic of Grenoble). From 2005 up to now, he is a research member of the LSIS. His main research activities deal with adaptive and robust control, signal processing, diagnosis and observation for complex systems such as vehicles and robots.

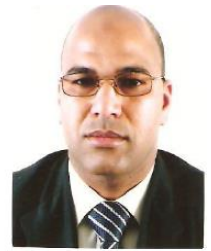

Mohamed Larbi Elhafyani is Professor at Mohamed first university, Oujda, Morocco and currently member at Electrical Engineering and Maintenance Laboratory (LGEM). He received with Honors the Ph.D degree in electrical machines \& power electronic (renewable energy), from faculty of science, university Mohamed first, Oujda in 2008. His current area of interest is related to the advanced control of wind turbine system, power electric and renewable energy. 